\title{
Amino Acid Mutation in Position 349 of Glycoprotein Affect the Pathogenicity of Rabies Virus
}

\author{
Jun Luo, Boyue Zhang, Yuting Wu and Xiaofeng Guo* \\ College of Veterinary Medicine, South China Agricultural University, Guangzhou, China
}

\section{OPEN ACCESS}

Edited by:

Francois Villinger,

University of Louisiana at Lafayette,

United States

Reviewed by:

Monique Lafon,

Institut Pasteur, France

Satoko Yamaoka,

Mayo Clinic, United States

*Correspondence:

Xiaofeng Guo

xfguo@scau.edu.cn

Specialty section:

This article was submitted to

Virology,

a section of the journal

Frontiers in Microbiology

Received: 19 November 2019

Accepted: 05 March 2020

Published: 03 April 2020

Citation:

Luo J, Zhang B, Wu Y and Guo X

(2020) Amino Acid Mutation

in Position 349 of Glycoprotein Affect

the Pathogenicity of Rabies Virus.

Front. Microbiol. 11:481.

doi: 10.3389/fmicb.2020.00481
Rabies, caused by rabies virus (RABV), is a zoonotic disease infecting mammals including humans. Studies have confirmed that glycoprotein $(\mathrm{G})$ is most related to RABV pathogenicity. In the present study, to discover more amino acid sites related to viral pathogenicity, artificial mutants have been constructed in G of virulent strain GD-SH01 backbone. Results showed that pathogenicity of GD-SH-01 significantly decreased when Gly 349 was replaced by Glu $_{349}$ through in vivo assays. Gly349 $\rightarrow \mathrm{Glu}_{349}$ of $\mathrm{G}$ did not significantly influence viral growth and spread in NA cells. Gly349 $\rightarrow \mathrm{Glu}_{349}$ of $\mathrm{G}$ increased the immunogenicity of GD-SH-01 in periphery and induced more expression of interferon alpha (IFN- $\alpha$ ) in the brain in mice. It was observed that $\mathrm{Gly}_{349} \rightarrow \mathrm{Glu}_{349}$ of $G$ led to enhanced blood-brain barrier (BBB) permeability at day 5 postinfection. All together, these data revealed that $\mathrm{Gly}_{349} \rightarrow \mathrm{Glu}_{349}$ of $\mathrm{G}$ mutation decreased RABV pathogenicity through enhanced immune response and increased BBB permeability. This study provides a new referenced site G349 that could attenuate pathogenicity of RABV.

\section{Keywords: rabies virus, mutation, pathogenicity, glycoprotein, immunogenicity}

\section{INTRODUCTION}

Rabies is an ancient zoonotic disease affecting the central nervous system (CNS) and continues to be a worldwide health problem. In humans, once the rabies symptoms manifest, the mortality rate is almost $100 \%$. The causative agent of rabies is the rabies virus (RABV), which causes fatal encephalitis in warm-blooded animals (Jackson, 2003). RABV, an unsegmented, negative-stranded RNA virus, belongs to the genus Lyssavirus of the family Rhabdoviridae. The RABV genome is $\sim 12 \mathrm{~kb}$ in size and comprises five genes, encoding nucleoprotein $(\mathrm{N})$, phosphoprotein $(\mathrm{P})$, matrix protein (M), glycoprotein (G), and the RNA-dependent RNA polymerase (L) (Schnell et al., 2010). Glycoprotein, the sole protein exposed on the surface of the virion, is the most important determinant of RABV pathogenicity and is the major protein to induce virus neutralizing antibody (VNA) (Dietzschold et al., 1983; Morimoto et al., 1999; Ito et al., 2001; Faber et al., 2002, 2004). Different RABV strains possess different virulence mainly based on the different sequences of G proteins. Amino acid residues 333, 194, 37, and 242/255/268 in G have been demonstrated to be strongly related to pathogenicity (Faber et al., 2005; Takayama-Ito et al., 2006a,b; Yamada et al., 2014b). However, mutations in the G protein that contribute to the pathogenicity are sometimes strain dependent (Takayama-Ito et al., 2004, 2006b). Therefore, it is likely that some amino acid residues correlated to virulence have still not been discovered and reported in the literature. RABV G is comprised of a signal peptide, an ectodomain, a transmembrane domain, and 
a cytoplasmic tail (Wunner et al., 1988; Kuzmina et al., 2013). The ectodomain and cytoplasmic of $\mathrm{G}$ have been linked to the pathogenicity and immune evasion of the virus (Coulon et al., 1998; Prehaud et al., 2010; Virojanapirom et al., 2012; Huang et al., 2017). In addition, four major and one minor antigenic sites of $\mathrm{G}$ were identified using monoclonal antibodies (Lafon et al., 1984; Benmansour et al., 1991). Residues 34-42 and 198200 of G have been recognized antigenic site II (Prehaud et al., 1988). Previous studies suggest that site III is from amino acids 330 to 338 in G (Seif et al., 1985; Wunner et al., 1988). Amino acid arginine at position 333 of $\mathrm{G}$, which locates in site III, is virulent for adult mice (Dietzschold et al., 1983; Tuffereau et al., 1989). Therefore, most of the antigenic sites described locate in ectodomain of glycoprotein.

A highly pathogenic GD-SH-01 strain, which caused pigs' death in a farm in Southern China, was isolated from a rabid pig (Luo et al., 2013). The analysis of whole-genome phylogeny and the comparison of nucleotide acid sequences suggested that the GD-SH-01 strain was closely associated with clade I of China, and it was found to be more pathogenic than challenge virus standard 24 (CVS-24) based on the pathogenicity index comparison (Luo et al., 2013). In an attempt to discover selective amino acids in $\mathrm{G}$ related to pathogenicity of RABV, and consequently provide some new referenced sites to generate highly attenuated rabies vaccines, we compared and analyzed the amino acid sequences of $\mathrm{G}$ from different RABV strains and conducted artificial amino acid mutation(s) on the backbone of GD-SH-01, with the corresponding amino acid(s) of HEP-Flury, which is one of the most attenuated rabies fixed strains and does not kill adult mice and was widely used as a vaccine strain (Fox et al., 1957; Sharpless et al., 1957; Morimoto et al., 2011). The pathogenicity of all mutants was then tested in adult mice. Here, we described a new amino acid site of RABV that related to its pathogenicity.

\section{MATERIALS AND METHODS}

\section{Cells, Viruses, and Animals}

Mouse neuroblastoma (NA) cells (Wuhan Institute of Biological Products, Wuhan, China) were cultured in Roswell Park Memorial Institute (RPMI) 1640 medium (Gibco, Suzhou, China) with 10\% fetal bovine serum (FBS) (Gibco, Grand Island, NY, United States). Baby hamster kidney (BHK-21) cells (Wuhan Institute of Biological Products, Wuhan, China) were maintained in Dulbecco's modified Eagle's medium (DMEM) (Gibco, Suzhou, China) containing 10\% FBS. HEP-Flury (from Jiangsu Academy of Agricultural Sciences, China) were propagated in NA cells. The virulent wild-type strain GD-SH-01 was previously isolated from a rabid pig (Luo et al., 2013). Mutant RABV containing $\operatorname{Arg}_{333} \rightarrow \mathrm{Gln}_{333}$ of G on the backbone of GD-SH-01 was rescued by our laboratory previously (unpublished data, here as a positive control of attenuated RABV strain). Female Kunming (KM) mice (6-7 weeks old), which are an outbreeding strain from Swiss mice, were purchased from the Center for Laboratory Animal Science of the Southern Medical University (Guangzhou, China). All animal experiments were performed under specific pathogenfree conditions in the Laboratory Animal Center of South China
Agricultural University. All animal experiments were approved by the Ethics Committee for Animal Experiments of the South China Agricultural University and conducted in compliance with National Institutes of Health (NIH) guidelines (Zhang et al., 2016). All possible efforts were made to minimize the suffering of laboratory animals.

\section{Selection of Amino Acid in G Protein}

To choose the potential amino acids that could attenuate RABV GD-SH-01 strain (Luo et al., 2012), several pathogenic and nonpathogenic RABV strains were selected, and the amino acid sequences of the G's ectodomain were compared, using MEGA 6 software [MEGA 6.06 (6140226)]. In this study, we selected partial strains including wild-type strains (from different hosts) and attenuated strains (pathogenic and non-pathogenic strains), together with interested wild-type strain GD-SH-01 (Table 1). The selected viral sequences were obtained from GenBank.

Amino acid site that determine pathogenicity of RABV is regularly different between pathogenic strains and nonpathogenic strains. Therefore, we selected amino sites that are different between pathogenic strains and non-pathogenic strains or between wild-type strains and attenuated strains. Therefore, selective amino acids, which differed in selected strains in the G of HEP-Flury were chosen: amino acid at position 19 in $G$ (G19), G194, and G349. In addition, different amino acid residue of G243 between wild-type and attenuated strains was selected. Amino acid residues in the G protein of GD-SH-01 that are different from most other selected strains were chosen: G96 and G132. The selected strains' information and amino acids are shown in Table 1. All the selected amino acid sites above were mutated artificially on the backbone of GD-SH-01 with the corresponding amino acid of HEP-Flury.

\section{Construction of the Mutant Full-Length Genome cDNAs and Rescue of the Viruses}

The plasmid containing the full-length genome complementary DNA (cDNA) of GD-SH-01 (rGDSH) was constructed and described previously (Tian et al., 2017). To construct the fulllength genome cDNA that contains the G19, G96, G132, G194, G243, or G349 mutations of GD-SH-01, the plasmid of rGDSH was amplified using respective primers (Table 2). The amino acids at respective position of GD-SH-01 were replaced with the corresponding amino acids of HEP-Flury. The seamless cloning was performed using One Step Cloning Kit (Vazyme Biotech, Nanjing, China) according to the manufacturer's protocols. Successful insertion was confirmed by DNA sequencing. All the mutant viruses were rescued in BHK-21 cells as described previously (Inoue et al., 2003; Luo et al., 2017). Rescued viruses were confirmed in NA cells by direct fluorescent antibody assay (dFA) with fluorescein isothiocyanate (FITC)-labeled anti-RABV $\mathrm{N}$ antibodies (Fujirabio Diagnostics, Malvern, PA, United States).

\section{Virus Propagation and Titration}

All the rescued mutant viruses (rGDSH-G19, rGDSH-G96, rGDSH-G132, rGDSH-G194, rGDSH-G243, and rGDSH-G349), 
TABLE 1 | Various rabies virus (RABV) strains information and selected amino acid position.

\begin{tabular}{|c|c|c|c|c|c|c|c|c|c|c|}
\hline \multicolumn{4}{|c|}{ Strains information } & \multicolumn{7}{|c|}{ Amino acid position } \\
\hline Strain & Host & GenBank No. & Passage & G19 & G96 & G132 & G194 & G243 & G333 & G349 \\
\hline HEP-Flury & Human & GU565704.1 & + & $\mathrm{L}$ & $A$ & $\mathrm{~L}$ & $\mathrm{H}$ & $M$ & $Q$ & $E$ \\
\hline GD-SH-01 & Pig & JX088694.1 & wt & I & S & $\mathrm{F}$ & $\mathrm{N}$ & 1 & $\mathrm{R}$ & G \\
\hline JX08-48 & Ferret badger & FJ719752.1 & wt & 1 & S & $\mathrm{F}$ & $\mathrm{N}$ & 1 & $\mathrm{R}$ & G \\
\hline GX4 & Dog & DQ849071.1 & wt & । & S & $\mathrm{F}$ & $\mathrm{N}$ & 1 & $\mathrm{R}$ & G \\
\hline HN10 & Human & EU643590.1 & wt & I & S & $\mathrm{F}$ & $\mathrm{N}$ & 1 & $\mathrm{R}$ & G \\
\hline F04 & Ferret badger & FJ712196.1 & wt & I & S & $\mathrm{F}$ & $\mathrm{N}$ & I & $R$ & G \\
\hline WH11 & Donkey & JQ647510.1 & wt & I & $\mathrm{T}$ & $L$ & $\mathrm{~N}$ & 1 & $\mathrm{R}$ & $G$ \\
\hline $\mathrm{SHO6}$ & Dog & FJ418886.1 & wt & 1 & A & $L$ & $\mathrm{~N}$ & 1 & $\mathrm{R}$ & $G$ \\
\hline CYN1009D & Dog & JQ730682.1 & $w t$ & 1 & A & $L$ & $\mathrm{~N}$ & 1 & $\mathrm{R}$ & $G$ \\
\hline BJ2011E & Equine & JQ423952.1 & wt & I & A & $L$ & $\mathrm{~N}$ & 1 & $\mathrm{R}$ & $G$ \\
\hline CQ92 & Dog & DQ849072.1 & wt & 1 & A & $L$ & $\mathrm{~N}$ & 1 & $\mathrm{R}$ & G \\
\hline $\mathrm{RC}-\mathrm{HL}$ & Cattle & AB009663.2 & + & 1 & $A$ & $L$ & $\mathrm{~N}$ & M & $\mathrm{R}$ & $\mathrm{G}$ \\
\hline $\mathrm{Ni}-\mathrm{CE}$ & Cattle & AB128149.1 & + & 1 & A & $L$ & $\mathrm{~N}$ & $M$ & $\mathrm{R}$ & G \\
\hline CVS-11 & Cattle & GQ918139.1 & + & 1 & $A$ & $L$ & $\mathrm{~N}$ & $M$ & $\mathrm{R}$ & $G$ \\
\hline CVS-B2c & Cattle & AF042824.1 & + & 1 & $A$ & $L$ & $\mathrm{~N}$ & M & $\mathrm{R}$ & $G$ \\
\hline CVS-N2c & Cattle & HM535790.1 & + & I & A & $L$ & $\mathrm{~N}$ & $M$ & $\mathrm{R}$ & $G$ \\
\hline SAD-B19 & Dog & M31046.1 & + & I & $A$ & $\mathrm{~L}$ & $\mathrm{~N}$ & $M$ & $\mathrm{R}$ & $G$ \\
\hline
\end{tabular}

"+", virus has been passaged in non-original host or culture cells; "wt," wild-type virus.

TABLE 2 | Primers used for construction of the mutant full-length genome complementary DNAs (cDNAs).

\begin{tabular}{|c|c|c|}
\hline Primers & Sequences of primers & nt changes \\
\hline rGDSH-G19-F & CCCATTGATITACATCATCTCAGCTGTCCGAATAATTTGGTTGTGG & $\mathrm{ATA} \rightarrow \mathrm{TTA}$ \\
\hline rGDSH-G19-R & TGAGATGATGTAAATCAATGGGACTCCAGGGACCGAGTTGTCTG & \\
\hline rGDSH-G96-F & TGCGTGCAGAGCCGCATACAATTGGAAGATGGCTGGTGACCCCAG & $\mathrm{TCC} \rightarrow \mathrm{GCC}$ \\
\hline rGDSH-G96-R & ATTGTATGCGGㅡTCTGCACGCATCCGGTGTTGGTCGAAAGTGC & \\
\hline rGDSH-G132-F & AAAGAGTCC트므GTCATCATATCTCCAAGTGTGGCAGATCTAG & $\Pi \Pi \rightarrow \mathrm{CTC}$ \\
\hline rGDSH-G132-R & TATGATGACGAGGGACTCПTGGTGGTIITACAGTCCGGAGC & \\
\hline rGDSH-G194-F & ATाTCACC드포AGCAGAGGGAAGAGAGCATCCAAAGGGAGC & $\mathrm{AAC} \rightarrow \mathrm{CAT}$ \\
\hline rGDSH-G194-R & СССTCTGCT묨GGGTGAAATATCACAAGAGGTTCCCAGTCTG & \\
\hline rGDSH-G243-F & TGGGTCGCAATGGCAGACATCAGACGAGACCAAGTGGTGCCCTC & $\mathrm{ATT} \rightarrow \mathrm{ATG}$ \\
\hline rGDSH-G243-R & CTGATGTCTG슷TGGGACCCATGTTCCATCCATAAGTCTAAG & \\
\hline rGDSH-G349-F & AGAGTTGGAGAGAGATGTCATCCCCATGTGAACGGGGTGTIITC & $\mathrm{GGC} \rightarrow \mathrm{GAG}$ \\
\hline rGDSH-G 349-R & GATGACATCT누CTCCAACTCTCAAACACCCTITAGAGGGGATG & \\
\hline
\end{tabular}

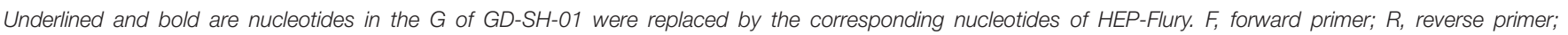
nt, nucleotides.

rGDSH-G333, HEP-Flury and GD-SH-01 were propagated in NA cells (Neuro-cells which is sensitive to RABV). Virus titers were determined by dFA as described previously (Luo et al., 2016). Briefly, NA or BHK-21 cells grown in 96-well cell-culture plates were inoculated with 10 -fold serial dilutions of the indicated virus in RPMI 1640 medium and incubated at $37^{\circ} \mathrm{C}$ with $5 \%$ $\mathrm{CO} 2$ for 2 days. Then, culture medium was discarded and cells were fixed with $80 \%$ acetone for $30 \mathrm{~min}$ at $-20^{\circ} \mathrm{C}$. Cells were washed with phosphate-buffered saline (PBS) three times and then stained with FITC-labeled anti-RABV $\mathrm{N}$ antibodies at $37^{\circ} \mathrm{C}$ for $60 \mathrm{~min}$. Subsequently, antigen-positive foci were counted under a fluorescence microscope (AMG, Washington, United States), and virus titers were calculated as focus forming units (FFUs) per milliliter (FFU/ml) using the Karber method (Ramakrishnan, 2016).

\section{Pathogenicity of RABV in Adult Mice}

Pathogenicity of mutant strains was conducted in adult mice. KM mice (6-7 weeks of age) were inoculated intramuscularly (i.m.) with $1.0 \times 10^{5}$ FFU or intracerebrally (i.c.) with $2.0 \times 10^{3}$ FFU of HEP-Flury, GD-SH-01, rGDSH-G19, rGDSH-G96, rGDSH-G132, rGDSH-G194, rGDSH-G243, rGDSH-G349, or rGDSH-G333 (as a positive control of attenuated RABV strain). Each group consisted of five or six mice. Mortality was recorded daily for 21 days.

\section{Virus Growth Curve in NA Cells}

Monolayer cultures of $2 \times 10^{6} \mathrm{NA}$ cells were infected with virus at a multiplicity of infection (MOI) of $0.1 \mathrm{FFU}$. Cells were then incubated at $37^{\circ} \mathrm{C}$ and harvested at 24, 48, 72, and $96 \mathrm{~h}$ 
postinoculation (hpi). Virus titers of samples were determined in NA cells by dFA, as described above. All titrations were carried out in triplicate.

\section{Virus Spread Assay}

The virus spread assay was performed in NA cells in 60$\mathrm{mm}$ cell cultural dishes as described previously (Mei et al., 2019). Briefly, monolayer NA cells were infected with RABV at an MOI of 0.01 and incubated at $37^{\circ} \mathrm{C}$. Cells were stained with FITC-labeled anti-RABV $\mathrm{N}$ antibodies at 24, 36, 48, and $60 \mathrm{hpi}$. Fluorescent foci in each dish were observed under a fluorescence microscope. The diameter of each fluorescent foci was measured using Adobe Photoshop CS software (Adobe, San Jose, United States) based on its scale. At least six fluorescent foci in each dish were measured.

\section{Virus-Neutralizing Antibody Investigation in Adult Mice}

Groups of five KM mice (6-7 weeks of age) were inoculated via the i.m. injection of $1.0 \times 10^{5}$ FFU rGDSH-G349 or GD-SH01. RPMI 1640 medium was used for mock infection. Serum was collected from caudal vein at 9 days postinfection (dpi) and used to determine VNA levels by means of fluorescent antibody virus neutralization (FAVN) tests, as described previously (Cliquet et al., 1998).

\section{Flow Cytometry}

Flow cytometry was carried out to investigate the percentage of immune cells in the spleen after RABV infection. Briefly, KM mice (6-7 weeks of age) were infected i.m. with $1.0 \times 10^{5}$ FFU of rGDSH-G349 or GD-SH-01 or RPMI 1640 medium, respectively. Mouse spleen were harvested at 9 dpi. Single-cell suspensions were prepared followed by treatment with red blood cell lysis buffer (Beyotime, Shanghai, China) following the manufacturer's instructions, and stained with antibodies against markers of $\mathrm{T}$ cells (FITC-CD3e, PE-CD4, PerCP-Cy5.5-CD8a) and B cells (FITC-CD19, PE-CD40) (all antibodies were purchased from Affymetrix eBioscience, United States) by incubation for $30 \mathrm{~min}$ on ice. A minimum of 50,000 events were counted using CytoFLEX flow cytometer (Beckman Coulter, United States). Data were analyzed using FlowJo software (Tree Star, Ashland, United States).

\section{Quantitative Real-Time PCR}

Kunming mice (6-7 weeks of age) were inoculated via the i.m. injection of $1.0 \times 10^{5}$ FFU rGDSH-G349 or GD-SH-01. At 5 and $9 \mathrm{dpi}$, mice were anesthetized with ketamine/xylazine $(100 / 10 \mathrm{mg} / \mathrm{kg})$ and then perfused by intracardiac injection of PBS. Whole brain tissues were harvested and then lysed in Magzol reagent (Magen, Guangzhou, China). Groups of three mice were used for each virus at one time point. Total RNA of each brain tissue sample was extracted using the HiPure Universal RNA Kit (Magen, Guangzhou, China) according to the manufacturer's protocol. Reverse transcription was carried out using the RevertAid First Strand
cDNA Synthesis Kit (Thermo Fisher Scientific, United States) following the manufacturer's instructions. Quantitative realtime PCR (qRT-PCR) was performed using SYBR Green Master Mix (Vazyme Biotech Co., Ltd., Nanjing, China) in a CFX Connect Real-Time System (Bio-Rad, Hercules, CA, United States). Expression levels of interferon alpha (IFN- $\alpha$ ) and immunoglobulin G (IgG) Ê-L chain were normalized to the house-keeping gene glyceraldehyde-3-phosphate dehydrogenase (GAPDH). Genomic RNA was determined with primers amplifying leader RNA and partial N. Primers used to amplify target and reference genes were described previously (Luo et al., 2017).

\section{Measurement of Viral Load in Periphery}

To evaluate RABV load at the inoculation site, KM mice (67 weeks of age) were inoculated in the right hind leg with $1.0 \times 10^{5}$ FFU rGDSH-G349 or GD-SH-01. After the mice were humanely killed, the right hind leg muscles of five mice from each group were removed from infected mice at 1, 3, 5, 7, and 9 dpi and grinded in liquid nitrogen and then lysed in Magzol reagent (Magen). Total RNA was extracted using the HiPure Universal RNA Kit (Magen), and qRT-PCR was performed as described previously (Wang et al., 2014) to determine RABV genomic RNA in muscles using primers amplifying leader RNA and partial N. Genomic RNA was normalized to GAPDH.

\section{Virus Growth Curve in Mouse Brain}

Rabies virus growth curves in vivo were performed in mouse brain. KM mice (6-7 weeks of age) were inoculated i.m. with $1.0 \times 10^{5}$ FFU of rGDSH-D255G or GD-SH-01 in $30 \mu \mathrm{l}$ RPMI 1640 medium. Three infected mice of each group were euthanized at $1,3,5,7$, and $9 \mathrm{dpi}$, and brains were harvested to detect the RABV genome using qRT-PCR as described previously (Luo et al., 2018). Three infected mouse brains were homogenized in a ninefold volume of RPMI 1640 medium and centrifuged at $12,000 \times g$ for $10 \mathrm{~min}$ at $4^{\circ} \mathrm{C}$ following repeated freezing and thawing to investigate virus titer in brains. Supernatants were harvested, and virus titer was determined as described above.

\section{Measurement of BBB Permeability Using Sodium Fluoride Uptake}

Groups of three KM mice (6-7 weeks of age) were inoculated via the i.m. injection of $1.0 \times 10^{5}$ FFU rGDSH-G349 or GD-SH-01. The mock-infected mice were treated with RPMI 1640 medium. Blood-brain barrier (BBB) permeability was measured through the uptake of sodium fluoride as described previously (Luo et al., 2018) at 1, 3, 5, and 9 dpi. Data are expressed as fold change relative to mockinfected mice.

\section{Statistical Analysis}

Data were analyzed using GraphPad Prism 6 software (GraphPad Software, San Jose, CA, United States). The statistical significance 
was determined using the Student's $t$-test. $P<0.05$ was considered to be significantly different.

\section{RESULTS}

\section{Rescue of Mutant Viruses}

Based on the full-length cDNA sequence of GD-SH-01, amino acid (Ile) at G19 was replaced by Leu ( $\left.\mathrm{Ile}_{19} \rightarrow \mathrm{Leu}_{19}\right)$, designated as rGDSH-G19; amino acid (Ser) at G96 was replaced by Ala $\left(\right.$ Ser $_{96} \rightarrow$ Ala $_{96}$ ), designated as rGDSH-G96; amino acid (Phe) at G132 was replaced by Leu $\left(\mathrm{Phe}_{132} \rightarrow \mathrm{Leu}_{132}\right.$ ), designated as rGDSH-G132; amino acid (Asn) at G194 was replaced by His $\left(\right.$ Asn $_{194} \rightarrow$ His $\left._{194}\right)$, designated as rGDSH-G194; amino acid (Ile) at G243 was replaced by Met ( $\mathrm{Ile}_{243} \rightarrow \mathrm{Met}_{243}$ ), designated as rGDSH-G243; and amino acid (Gly) at G349 was replaced by Glu ( $\mathrm{Gly}_{349} \rightarrow \mathrm{Glu}_{349}$ ), designated as rGDSHG349. Mutant RABV containing $\operatorname{Arg}_{333} \rightarrow \mathrm{Gln}_{333}$ of $\mathrm{G}$ on the backbone of GD-SH-01 was termed rGDSH-G333 (Figure 1). The mutant strains were rescued in BHK-21 cells and each virus was verified in NA cells by immunofluorescence staining using FITC-conjugated antibodies against RABV $\mathrm{N}$ protein. Successful single amino acid mutation was confirmed by DNA sequencing.

\section{Pathogenicity of Mutant Strains in Adult Mice}

To investigate if the selected mutations really attenuated the pathogenicity of RABV, adult KM mice (6-7 weeks) were i.m. or i.c. inoculated with each mutant strain. As shown in Figure 2, virulent strain GD-SH-01 caused $100 \%$ mortality by $14 \mathrm{dpi}$, while, as expected, all the mice survived the infection with the avirulent HEP-Flury through both i.m. and i.c. infection. As shown in Figure 2A, mutants rGDSH-G19, rGDSH-G96, rGDSH-G132, rGDSH-G194, and rGDSH-G243 caused 40, 60, 20, 20, and 40\% mortality, respectively, while rGDSH-G349 caused no mice death through i.m. infection, same as the contrast group rGDSH-G333. As shown in Figure 2B, mutants rGDSHG19, rGDSH-G96, rGDSH-G132, rGDSH-G194, and rGDSHG243 caused 100\% mortality, while rGDSH-G349 caused 50\% mortality through i.c. infection. Contrast group rGDSH-G333 did not kill adult mice through i.c. infection (Figure 2B). These results indicated that mutations of G19, G96, G132, G194, or G243 decreased parental pathogenicity after i.m. inoculation, whereas they displayed the same level of pathogenicity as the parent GD-SH-01 after i.c. inoculation. In contrast, the G349 mutation showed to be a promising mutation, as it significantly attenuated GD-SH-01 without killing adult mice through i.m. inoculation.

\section{Virus Growth Curve in NA Cells}

Gly $_{349} \rightarrow$ Glu $_{349}$ of G significantly decreased RABV pathogenicity as described above. We therefore will focus on the investigation of rGDSH-G349. The in vitro growth curves of rGDSHG349 were investigated in NA cells. As shown in Figure 3A, G349 mutation strain showed same growth curves compared with parent GD-SH-01. However, rGDSH-G349 reached the highest virus titers at $72 \mathrm{hpi}$, which was higher than GD-SH-01.

\section{Spread of Viruses in NA Cells}

$G$ exposed on the surface of virion that is responsible for the interaction with host cells. Here, we investigated whether G349 mutations affect viral spread in NA cells. As shown in Figures 3B,C, Gly ${ }_{349} \rightarrow \mathrm{Glu}_{349}$ mutation in $\mathrm{G}$ did not affect viral spread compared with parent GD-SH-01.

\section{Immunogenicity of rGDSH-G349 in Adult Mice}

After discovering that rGDSH-G349 significantly attenuated GDSH-01 pathogenicity, an attempt was made to investigate its immunogenicity, which is essential in the clearance of RABV (Kaplan et al., 1975; Hooper et al., 1998). To investigate the immune response after $\mathrm{Gly}_{349} \rightarrow \mathrm{Glu}_{349}$ mutation, flow cytometry was conducted to determine contents/counts of CD19 + CD40 + B cells, CD4 + T cells, and CD8 + T cells in spleen at 9 dpi. Figure $4 \mathrm{~A}$ illustrates the gating strategy to identify CD19 + CD40 + B cells, and Figure 4B illustrates the gating strategy to identify CD $4+\mathrm{T}$ cells and CD8 $+\mathrm{T}$ cells. As shown in Figure 4C, rGDSH-G349 recruited more CD19 + CD40 + B cells and CD8 + T cells (from CD3 + T cells) than parent GD$\mathrm{SH}-01$ in the spleen after i.m. infection. The counts of CD4 $+\mathrm{T}$ cells (from CD3 + T cells) induced by GD-SH-01 were more than those induced by rGDSH-G349.

Virus neutralizing antibody in the periphery blood was determined at 9 dpi in mice after i.m. infection. As shown in Figure 5A, rGDSH-G349 was able to induce a higher level of VNA in periphery compared with parent GD-SH-01. In sum, Gly $349 \rightarrow$ Glu $_{349}$ mutation in GD-SH-01 strain enhances its immunogenicity in mice.

\section{Viral Load of RABV at Inoculation Site}

Viral load of RABV at the inoculation site was evaluated in KM mice after i.m. infection with rGDSH-G349 or GD-SH-01. As shown in Figure 5B, more genomic RNA of rGDSH-G349 than parent GD-SH-01 were determined at 5 and 7 dpi. Comparable viral load were detected in mice infected with rGDSH-G349 and GD-SH-01 at 1, 3, and 9 dpi.

\section{Immune Effectors in CNS After RABV Infection}

To investigate the innate immune response caused by RABVs in CNS, mice were immunized with rGDSH-G349 or GD-SH-01 via i.m. route. The messenger RNA (mRNA) levels of IFN- $\alpha$ was investigated using qRT-PCR. As shown in Figure 6A, rGDSHG349 induced more IFN- $\alpha$ than parent GD-SH-01 at 5 dpi. This indicated that G349 mutation induced a stronger innate immune response in CNS at early stage.

IgG $\kappa-\mathrm{L}$ chain mRNA expression was determined to evaluate antibody level in brain tissues (Phares et al., 2006; Lebrun et al., 2015). As shown in Figure 6B, rGDSH-G349 induced more expression of IgG $\hat{\mathrm{E}}-\mathrm{L}$ chain than parent GD-SH-01 at 


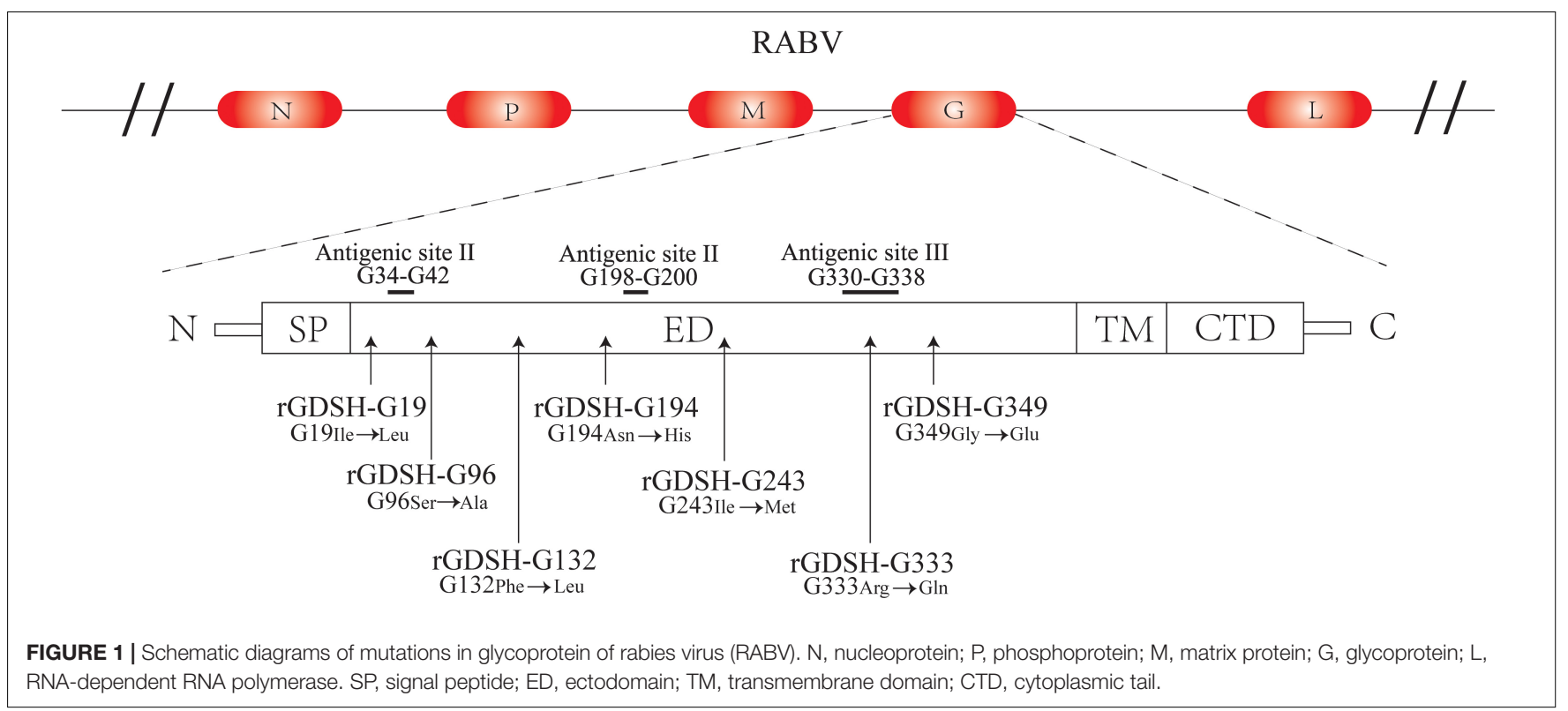

A
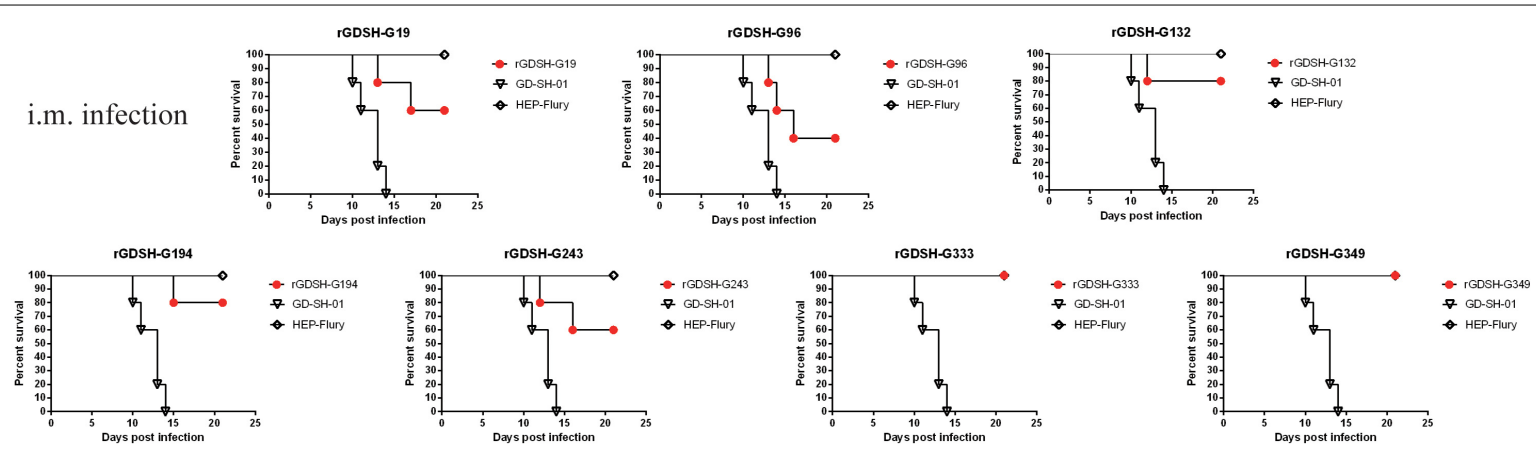

$\bar{B}$
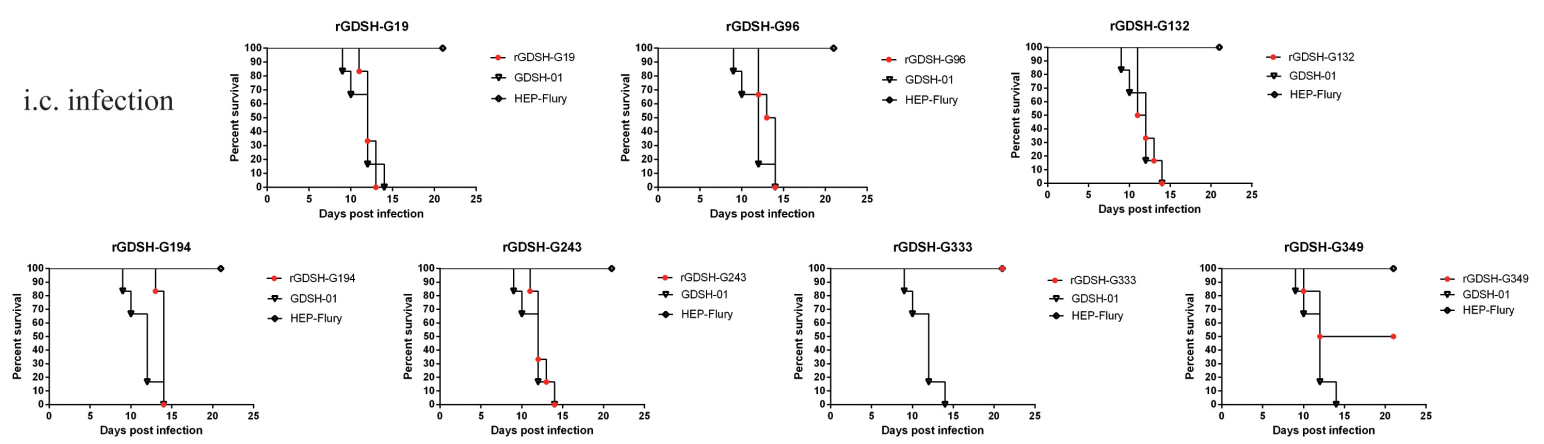

FIGURE 2 | Pathogenicity of mutant rabies virus (RABV) strains in adult mice. Female Kunming (KM) mice (6-7 weeks of age) were inoculated i.m. (A) with $1.0 \times 10^{5}$ or i.c. (B) with $2.0 \times 10^{3} \mathrm{FFU}$ of HEP-Flury, GD-SH-01, rGDSH-G19, rGDSH-G96, rGDSH-G132, rGDSH-G194, rGDSH-G243, rGDSH-G333, or rGDSH-G349. Each group consisted of five or six mice. Mortality was recorded daily for 21 days.

5 dpi. rGDSH-G349 infection triggered more immune effectors infiltrated into CNS than GD-SH-01.

\section{Virus Growth Curve in Mouse Brain}

Mice were inoculated i.m. with rGDSH-G349 or GD-SH01 , and viral genomes and live virus particles were detected at various times postinoculation to further investigate whether G349 mutation affect virus replication in the CNS. Comparable viral genome and live virus particle levels were detected in mice infected between rGDSH-G349 and GDSH-01 at 1, 3, and 5 dpi (Figure 7). However, the levels of viral genome and live virus particle of rGDSH-G349 
A

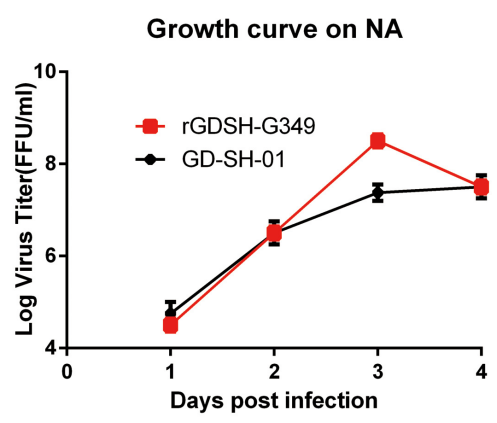

B

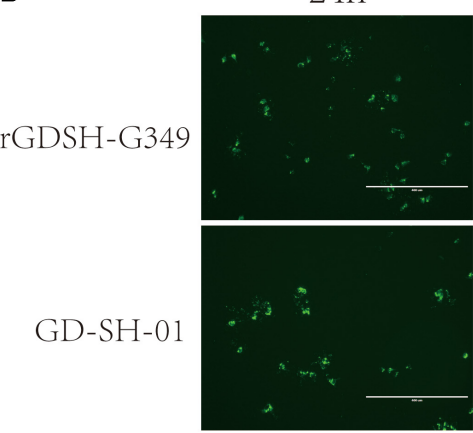

C

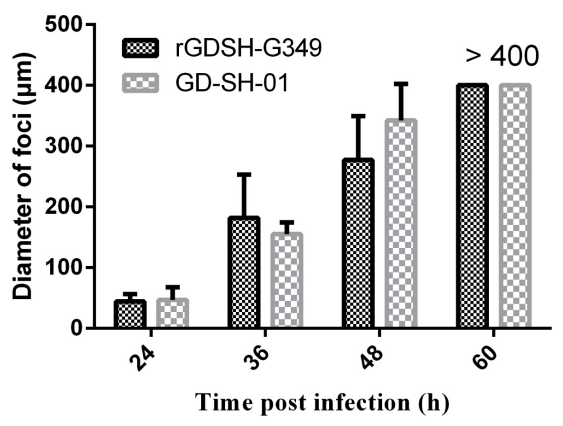

$48 \mathrm{~h}$
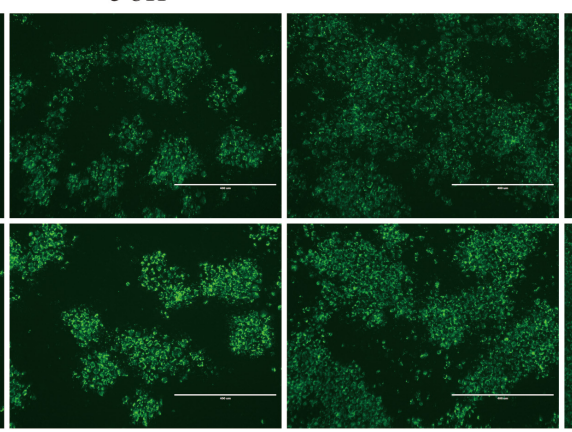

$60 \mathrm{~h}$

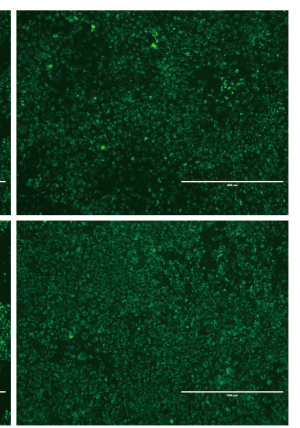

FIGURE 3 | Growth curves and spread ability of rabies virus (RABV) in NA cells. (A) Growth curves. NA cells were infected with rGDSH-G349 or GD-SH-01, respectively, at a multiplicity of infection (MOI) of 0.1 . At 1, 2, 3, and 4 dpi, culture supernatants were harvested, and virus titers were determined. (B,C) Viral spread in NA cells. Monolayer NA cells were infected with rGDSH-G349 or GD-SH-01 at an MOI of 0.01 and incubated at $37^{\circ} \mathrm{C}$. Cells were stained with fluorescein isothiocyanate (FITC)-labeled anti-rabies virus (RABV) N antibodies at 24, 36, 48, and $60 \mathrm{hpi}$. The stained cells were examined under a fluorescence microscope, and for each group, the presentative image out of three replicates was shown (B). (C) The diameter of each fluorescent foci was measured based on its scale. Data are presented as mean values \pm SE.

were significantly lower than that of GD-SH-01 at 7 and 9 dpi (Figure 7).

\section{BBB Permeability Caused by rGDSH-G349 in Adult Mice}

Enhanced BBB permeability may contribute to the clearance of infected RABV in CNS. Here, we investigated whether G349 mutation changed BBB permeability after infection. As shown in Figure 8, mice infected with rGDSH-G349 exhibited increased levels of $\mathrm{NaF}$ compared with GD-SH-01 in both the cerebrum and cerebellum at $5 \mathrm{dpi}$. This suggests that G349 mutation strain enhanced BBB permeability.

\section{DISCUSSION}

Reverse genetic technology is a powerful tool to investigate RABV, and it has been used since the first RABV was rescued from cloned cDNA (Schnell et al., 1994). Since then, several studies have successfully used reverse genetic technology to construct mutant strains of RABV to investigate their pathogenicity or immunogenicity (Takayama-Ito et al., 2006a,b; Yamada et al., 2014b; Nakagawa et al., 2017). Previous studies have confirmed that $\mathrm{Ala}_{242}, \mathrm{Asp}_{255}, \mathrm{Ile}_{268}, \mathrm{Lys}_{330}$, and $\mathrm{Arg}_{333}$ are all involved in viral pathogenicity (Tuffereau et al., 1989; Coulon et al., 1998; Faber et al., 2005; Takayama-Ito et al., 2006b), suggesting that more than one amino acid are associated with RABV pathogenicity. Here, we speculate that, in addition to the reported amino acid, other novel amino acid sites in $G$ determine the pathogenicity of RABV. By comparing the ectodomain of $G$ from various strains, we selected six potential amino sites, which might be related to pathogenicity of RABV. In this study, mutations were conducted in the backbone of GD-SH01, which is a highly virulent strain isolated from pig (Luo et al., 2013). To illustrate the relationship between amino acid site and pathogenicity, the viral strain was compared to the avirulent strain HEP-Flury, and the corresponding referenced amino acids were matched and replaced. All the mutant strains were rescued, and the pathogenicity was investigated. Here, we found that $\mathrm{Gly}_{349} \rightarrow \mathrm{Glu}_{349}$ mutation in G decreased RABV pathogenicity, which was not reported previously.

Interestingly, the comparison of selected $G$ gene sequences highlighted that the HEP-Flury strain exclusively contained Glu at G349, while other strains contained a Gly in that position (Table 1). In addition, only HEP-Flury strain presented Gln at G333, while other strains (in Table 1) contained an Arg. Previous studies had indicated that pathogenicity of RABV decreased significantly when Arg or Lys at G333 was replaced by other 
A
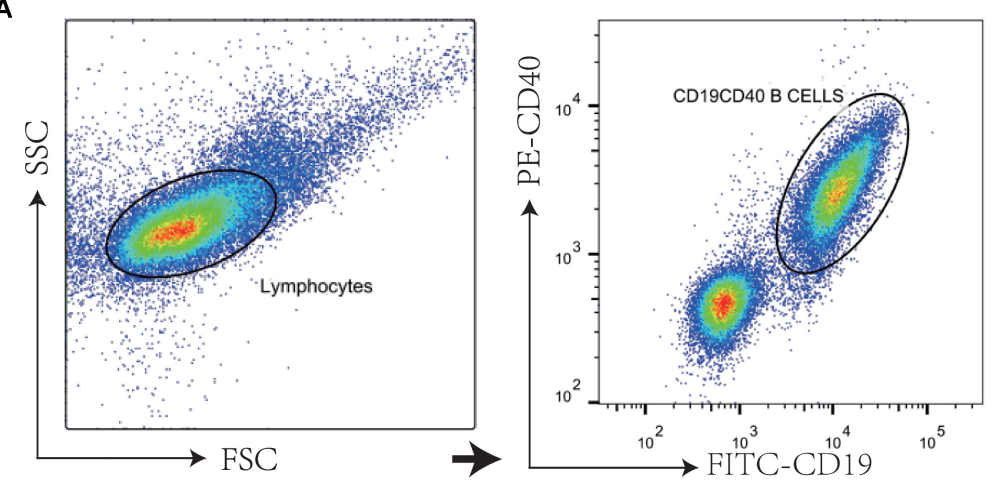

B
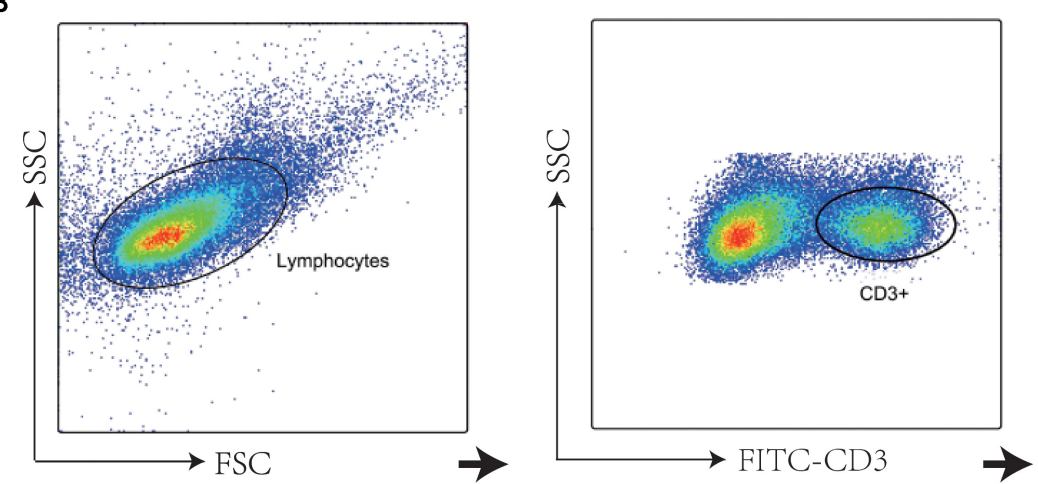

C
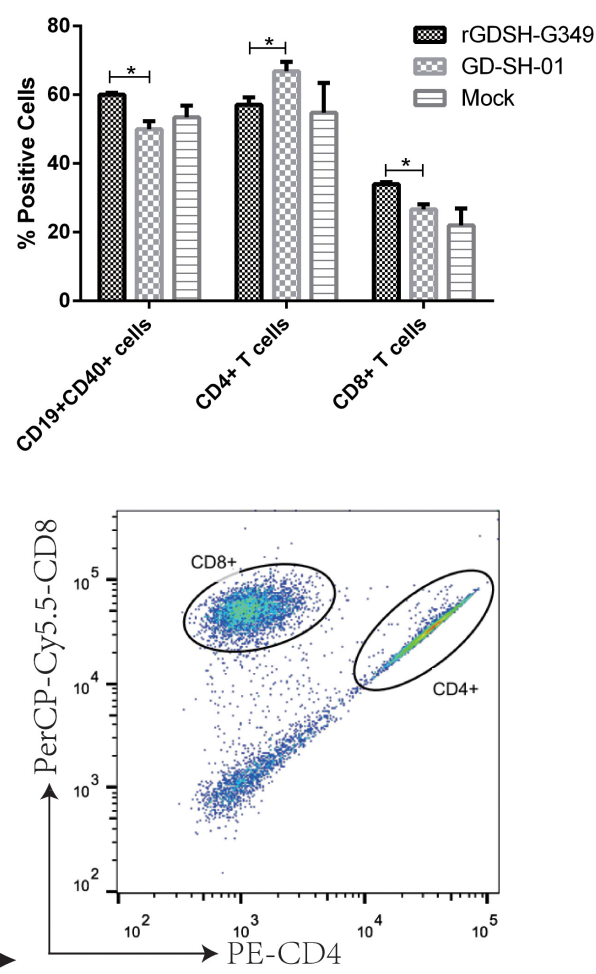

FIGURE 4 | Flow cytometric analysis of immune cells in spleen. Female KM mice (6-7 weeks of age) were infected i.m. with $1.0 \times 10^{5}$ FFU of rGDSH-G349, GD-SH-01, or medium alone (mock infection). Spleens were harvested at $9 \mathrm{dpi}$, and single-cell suspensions were prepared and stained with antibodies against markers of T cells (FITC-CD3e, PE-CD4, PerCP-Cy5.5-CD8a) and B cells (FITC-CD19, PE-CD40). Data were collected and analyzed with a CytoFLEX flow cytometer (Beckman Coulter) and FlowJo software (Tree Star). (A) Representative flow cytometric pseudocolor showing the gating strategy to identify CD19 + CD40 + B cells. (B) Representative flow cytometric pseudocolor showing the gating strategy to identify CD4 + T cells and CD8 + T cells. (C) Percentages of CD19 + CD40 + B cells, CD4 + T cells and CD8 + T cells in spleen ( $n \geq 3$ per group). Values are presented as mean \pm SE. Asterisks indicate significant differences between groups, as calculated by Student's $t$-test $\left({ }^{\star} P<0.05\right)$.
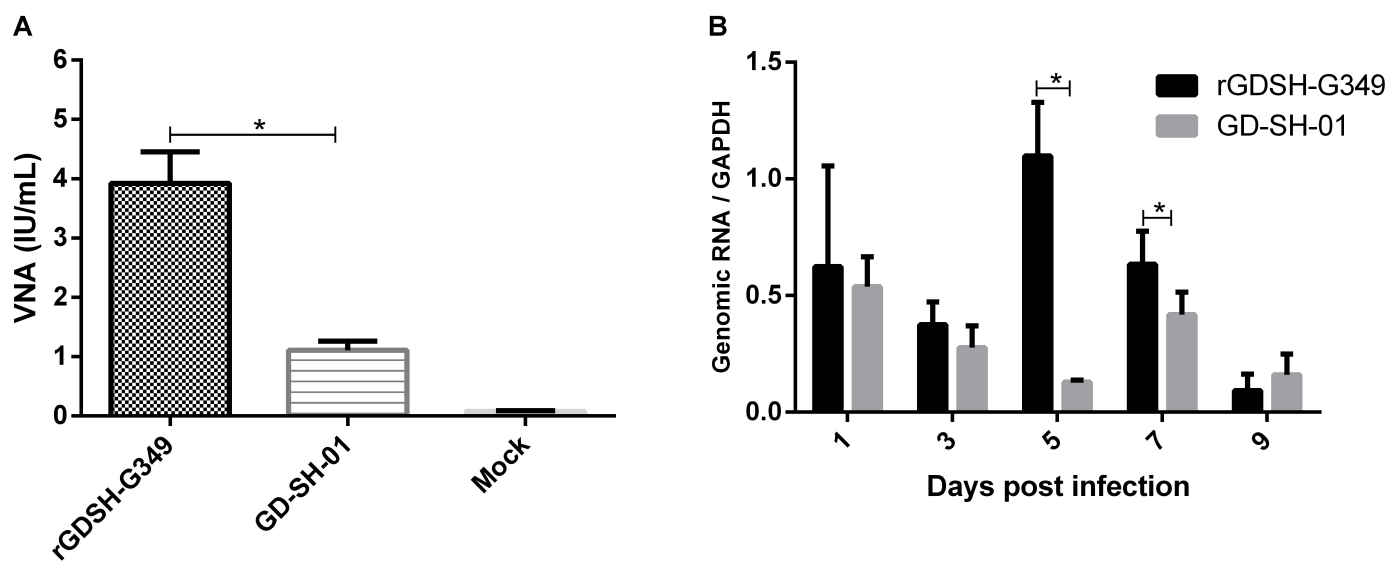

FIGURE 5 | (A) Virus neutralizing antibody (VNA) in periphery. Groups of five female Kunming (KM) mice (6-7 weeks of age) were inoculated i.m. with $1.0 \times 10^{5}$ FFU of rGDSH-G349, GD-SH-01 or medium alone (mock infection). Peripheral blood was obtained at 9 dpi, and serum virus-neutralizing antibody was ascertained using fluorescent antibody virus neutralization test, as described in section "Materials and Methods." (B) Viral load at inoculation site. KM mice (6-7 weeks of age) were inoculated in the right hind leg with $1.0 \times 10^{5} \mathrm{FFU}$ rGDSH-G349 or GD-SH-01 and the right hind leg muscles were collected from infected mice at 1, 3, 5, 7, and 9 dpi. Genomic RNA of RABV were investigated by quantitative real-time PCR in a CFX Connect Real-Time System. Expression level were normalized to the housekeeping gene GAPDH messenger RNA (mRNA). Data were analyzed using BioRad CFX Manager and GraphPad Prism 6. Results were shown as the mean \pm SE. Asterisks indicate significant differences between groups, as analyzed by $t$-test $\left({ }^{*} P<0.05\right)$. 
A

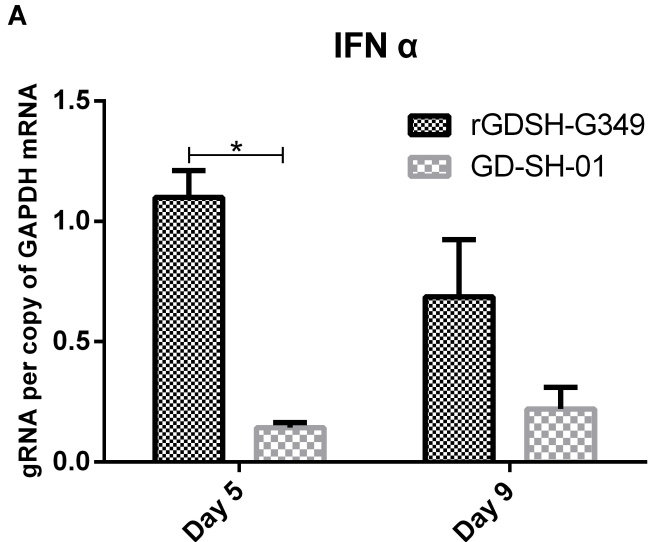

B

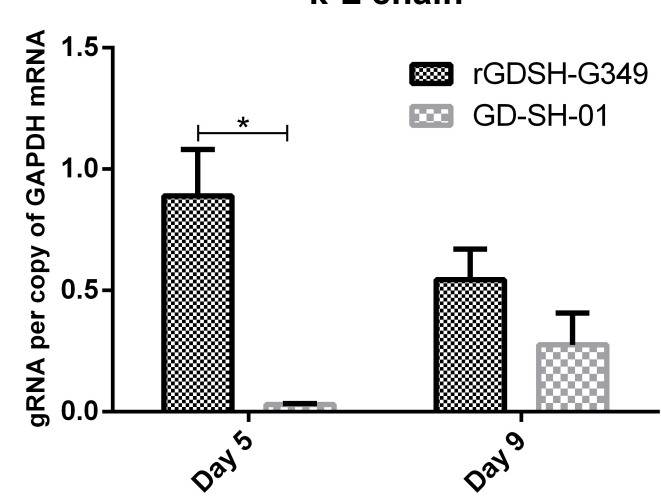

FIGURE 6 | Expression of interferon alpha (IFN- $\alpha$ ) (A) and immunoglobulin G (lgG) Ê-L chain (B) in the CNS. Female adult Kunming (KM) mice were inoculated i.m. with $1.0 \times 10^{5} \mathrm{FFU}$ of rGDSH-G349 orGD-SH-01. At 5 and 9 dpi, mice were anesthetized, and brains were harvested following the perfusion with PBS. Expression of interferon alpha (IFN- $\alpha$ ) and immunoglobulin G (IgG) $\hat{E}$-L chain in brain tissues were investigated by quantitative real-time PCR in a CFX Connect Real-Time System. Expression level were presented per copy of the housekeeping gene glyceraldehyde-3-phosphate dehydrogenase (GAPDH) messenger RNA (mRNA0. Results were shown as the mean \pm SE. Asterisks indicate significant differences among groups, as calculated by Student's $t$-test $\left.{ }^{\star} P<0.05\right)$.

A

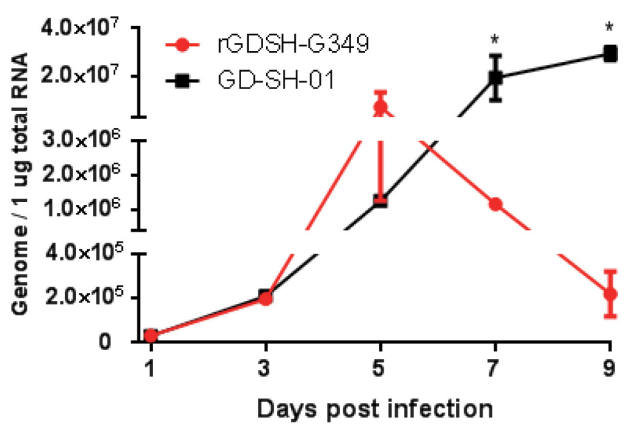

B

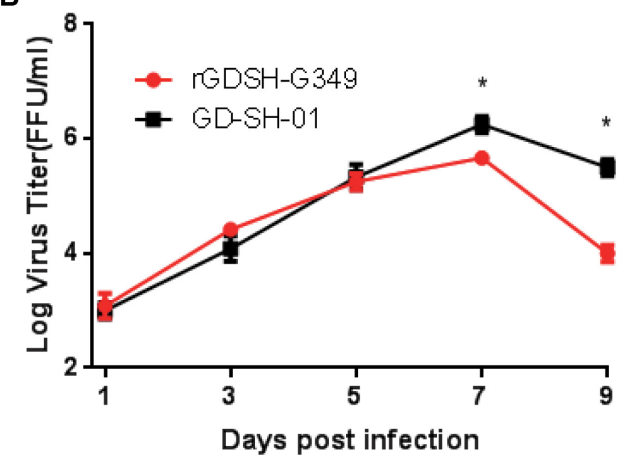

FIGURE 7 | Growth curves of rGDSH-G349 and GD-SH-01 in mouse brain. Kunming (KM) mice were inoculated with $1.0 \times 10^{5}$ FFU of rGDSH-G349 or GD-SH-01 via an i.m. route. Mice were euthanized at 1, 3, 5, 7, and 9 dpi, and brains were harvested to determine rabies virus (RABV) genome (A) using quantitative real-time PCR and live virus titers (B) as described in Materials and Methods. Three mice were used for RABV genome investigations, and three mice were used for virus titers investigations per group. Data are presented as mean values \pm SE. Asterisks indicate significant differences between the two groups, as calculated using Student's t-test $\left({ }^{*} P<0.05\right)$.

amino acids (Seif et al., 1985; Tuffereau et al., 1989; Tao et al., 2010). Therefore, selecting potential sites present in avirulent strains, but not in virulent strains, is an approved strategy for studying the effect of mutation on pathogenicity. Of note, RC-HL strain contains Arg at G333, but it is an avirulent strain (Ito et al., 1994); therefore, mutations related to pathogenicity of RABV are strains dependent. Further studies are necessary to investigate if Glu at G349 could attenuate other RABV strains.

Previous study indicates that by exchanging the ectodomain of $\mathrm{G}$ from wild-type with attenuated RABVs, the virus titers and spread ability were altered (Huang et al., 2017). In this study, we discovered that the single mutation at G349 did not significantly alter the virus growth curves and spread ability in NA cells. It has been reported that multiple mutations at positions 252/255/268 of $\mathrm{G}$ protein of RC-HL strain did not alter the virus titers in NA cells (Ito et al., 2010). However, single amino mutation at position
37 or 146 of G protein of 1088 strain significantly increased virus replication in NA cells (Yamada et al., 2014b). In addition, mutation of $A_{194}$ of $G$ protein attenuated strain SPBNGA with Ser had no effect on virus production, while mutation with Lys decreases virus production (Faber et al., 2005). These previous findings suggest that whether a single or multiple mutations of the $G$ protein of $R A B V$ really exerts effect on virus replication is dependent on the specific mutant site or the specific RABV strains, or on both events.

Previous studies indicate that R196S mutation and D247N mutation of $\mathrm{G}$ in strain 1088 variants, which led to an additional $N$-glycosylation and decrease in pathogenicity of RABV (Yamada et al., 2014a,b). Therefore, $N$-glycosylation in G may influence pathogenicity of RABV (Yamada et al., 2014b). In this study, G349 mutation does not increase or decrease $N$-glycosylation. Normally, pathogenic RABV infection causes adult mice death 

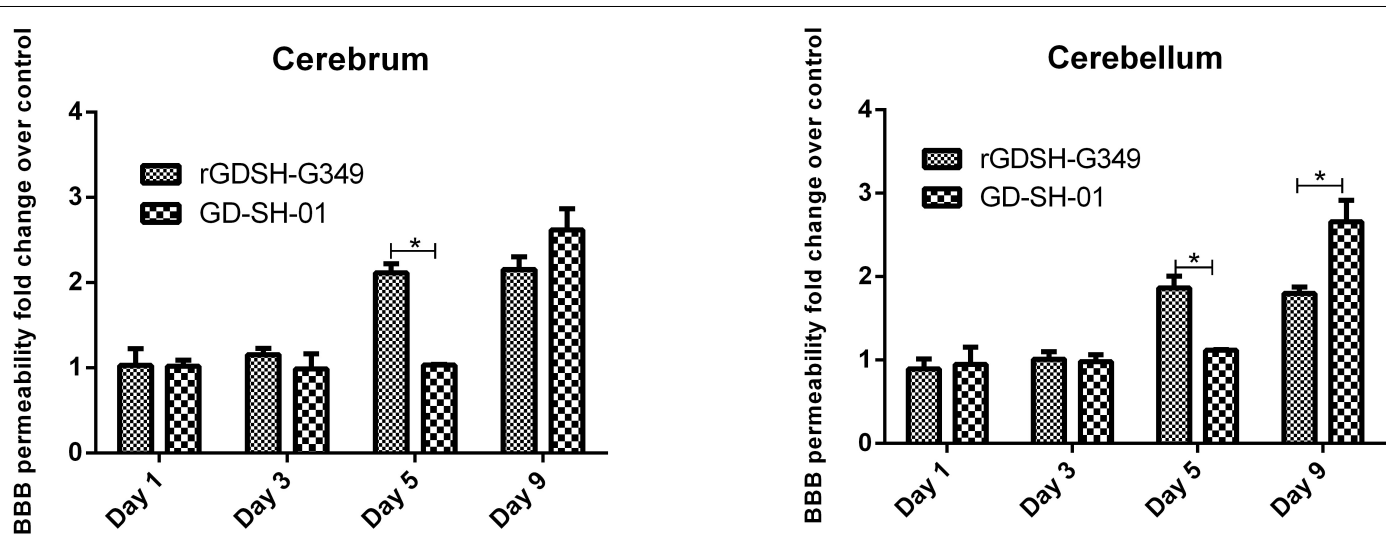

FIGURE 8 | Blood-brain barrier (BBB) permeability in the cerebrum and cerebellum of mice infected with rabies virus (RABV). Kunming (KM) mice (6-7 weeks old) were inoculated i.m. with either rGDSH-G349 or GD-SH-01. RPMl 1640 medium was used for the mock infection. At 1, 3, 5, or 9 dpi, brains were harvested, and BBB permeability was measured by NaF uptake in the cerebrum and cerebellum. Data are presented as fold change over mock infection. *Indicate significant differences among groups, as calculated by Student's $t$-test $\left({ }^{*} P<0.05\right)$.

while, attenuated RABV does not kill adult mice (Clark, 1978; Morimoto et al., 1998; Takayama-Ito et al., 2004; Shimizu et al., 2007; Tao et al., 2010; Wirblich and Schnell, 2011; Tian et al., 2016; Miao et al., 2017). Here, we found that mutation from Gly to Glu at G349 significantly attenuated GD-SH-01, the same as mutation of G333, without killing adult mice by i.m. inoculation. Neuroinvasiveness do not contribute to the attenuated virulence of G349 mutation because rGDSH-G349 showed the same growth ability compared with parent GD-SH-01 at an early stage of infection in the CNS. There must be other factors that direct the clearance of infected rGDSH-G349. Both innate immune response and adaptive immune response are essential in the clearance of RABV (Kaplan et al., 1975; Hooper et al., 1998; Chopy et al., 2011).

$\mathrm{G}$ plays the most important role in the induction of VNA (Cox et al., 1977). A previous study has confirmed that variant 1088-N30 induces higher level of VNA than street strain 1088 in serum in the earlier phase of infection after i.m. inoculation (Yamada et al., 2012). In this study, we found that VNA titer in mice induced by rGDSH-G349 was higher than parent GDSH-01 after i.m. infection. What's more, rGDSH-G349 recruited more CD19 + CD40 + B cells and CD8 + T cells in spleen. The immunogenicity of rGDSH-G349 is stronger than GD-SH01 , and this may be due to more viral load at inoculation site as the results showed. In addition, $\mathrm{Gly}_{349} \rightarrow \mathrm{Glu}_{349}$ mutation attenuated RABV pathogenicity, and this may contribute to the activation of dendritic cells (Yang et al., 2015). In addition, G349 mutation enhanced IgG Ê-L chain and IFN- $\alpha$ expression in CNS. Therefore, the enhanced innate immune response in CNS and infiltration of immune effectors induced by G349 mutation might contribute to the clearance of infected RABV. This explained why the virus load of rGDSH-G349 decreased at a late stage of infection in CNS.

Recent studies have confirmed the crystal structures of RABV $G$ and its interaction with neutralizing antibodies (Hellert et al., 2020; Yang et al., 2020). Residues from G333-G350 of ectodomain from three strains (CVS-11, Flury, and SAD-B19) are observed to bond to antibody 523-11 (Yang et al., 2020). They also found that antibody 523-11 could block the G-mediated syncytia formation of CVS-11, Flury, and SAD-B19 strains. However, antibody 523-11 only inhabits the infection of cells by Flury. The different residues from G333 to G350 were G333 (Gln: Arg) and G349 (Glu: Gly) between Fulry and CVS-11or SADB19. In this study, interested G349 locates the region that is a target of neutralizing antibodies, and its mutation may change the interaction with host cells. Further work is needed to confirm this speculation.

Enhanced BBB permeability caused by attenuated RABV also contribute to the clearance of infected RABV (Phares et al., 2006; Roy et al., 2007; Hooper et al., 2009; Chai et al., 2015). In this study, we found that rGDSH-G349 rather than parent GD-SH-01 significantly enhanced BBB permeability at 5 dpi. This might contribute to the enhanced inflammation in CNS and subsequently clear the infected RABV. In addition, VNA in serum may also contribute to the clearance of RABV in the CNS when BBB permeability opens (Huang et al., 2014). rGDSH-G349 induced higher levels of VNA in periphery after i.m. infection.

Previous studies indicated that attenuation caused by a single mutation in G of RBAV may revert according to reverse mutation or new mutation occurred in other amino acid site (Faber et al., 2005; Tao et al., 2010). Multiple amino acid changes could extensively attenuate the pathogenicity of RBAV and improve the stability of attenuation phenotype (Mebatsion, 2001; Dietzschold et al., 2004; Faber et al., 2005; Masatani et al., 2011; Nakagawa et al., 2017). Therefore, G349 could be a potential site when construct multiple amino acid changes to extensively attenuate the RABV pathogenicity.

In summary, by comparing the amino acid sequence of $G$ from different RABV strains, we selected six potential pathogenic amino acid positions. $\mathrm{Gly}_{349} \rightarrow \mathrm{Glu}_{349}$ mutation in G significantly decreased RABV pathogenicity through enhanced immune response rather than decreased replication. G349 mutation enhanced $\mathrm{BBB}$ permeability and might contribute to the 
clearance of RABV in CNS. In conclusion, this study discovered a new amino acid site of RABV related to pathogenicity.

\section{DATA AVAILABILITY STATEMENT}

The datasets generated for this study are available on request to the corresponding author.

\section{ETHICS STATEMENT}

The animal study was reviewed and approved by the Ethics Committee for Animal Experiments of the South China Agricultural University.

\section{REFERENCES}

Benmansour, A., Leblois, H., Coulon, P., Tuffereau, C., Gaudin, Y., Flamand, A., et al. (1991). Antigenicity of rabies virus glycoprotein. J. Virol. 65, 4198-4203. doi: 10.1128/jvi.65.8.4198-4203.1991

Chai, Q., She, R., Huang, Y., and Fu, Z. F. (2015). Expression of neuronal CXCL10 induced by rabies virus infection initiates infiltration of inflammatory cells, production of chemokines and cytokines, and enhancement of bloodbrain barrier permeability. J. Virol. 89, 870-876. doi: 10.1128/JVI.021 54-14

Chopy, D., Detje, C. N., Lafage, M., Kalinke, U., and Lafon, M. (2011). The type I interferon response bridles rabies virus infection and reduces pathogenicity. J. Neurovirol. 17, 353-367. doi: 10.1007/s13365-011-0041-6

Clark, H. F. (1978). Rabies viruses increase in virulence when propagated in neuroblastoma cell culture. Science 199, 1072-1075. doi: 10.1126/science. 628831

Cliquet, F., Aubert, M., and Sagne, L. (1998). Development of a fluorescent antibody virus neutralisation test (FAVN test) for the quantitation of rabiesneutralising antibody. J. Immunol. Methods 212, 79-87. doi: 10.1016/s00221759(97)00212-3

Coulon, P., Ternaux, J. P., Flamand, A., and Tuffereau, C. (1998). An avirulent mutant of rabies virus is unable to infect motoneurons in vivo and in vitro. J. Virol. 72, 273-278. doi: 10.1128/jvi.72.1.273-278.1998

Cox, J. H., Dietzschold, B., and Schneider, L. G. (1977). Rabies virus glycoprotein. II. Biological and serological characterization. Infect. Immun. 16, 754-759. doi: 10.1128/iai.16.3.754-759.1977

Dietzschold, B., Wunner, W. H., Wiktor, T. J., Lopes, A. D., Lafon, M., Smith, C. L., et al. (1983). Characterization of an antigenic determinant of the glycoprotein that correlates with pathogenicity of rabies virus. Proc. Natl. Acad. Sci. U.S.A. 80, 70-74. doi: 10.1073/pnas.80.1.70

Dietzschold, M. L., Faber, M., Mattis, J. A., Pak, K. Y., and Schnell, M. J. (2004). In vitro growth and stability of recombinant rabies viruses designed for vaccination of wildlife. Vaccine 23, 518-524. doi: 10.1016/j.vaccine.2004.06.031

Faber, M., Faber, M. L., Papaneri, A., Bette, M., Weihe, E., Dietzschold, B., et al. (2005). A single amino acid change in rabies virus glycoprotein increases virus spread and enhances virus pathogenicity. J. Virol. 79, 14141-14148. doi: 10. 1128/jvi.79.22.14141-14148.2005

Faber, M., Pulmanausahakul, R., Hodawadekar, S. S., Spitsin, S., McGettigan, J. P., Schnell, M. J., et al. (2002). Over expression of the rabies virus glycoprotein results in enhancement of apoptosis and antiviral immune response. J. Virol. 76, 3374-3381. doi: 10.1128/jvi.76.7.3374-3381.2002

Faber, M., Pulmanausahakul, R., Nagao, K., Prosniak, M., Rice, A. B., Koprowski, H., et al. (2004). Identification of viral genomic elements responsible for rabies virus neuroinvasiveness. Proc. Natl. Acad. Sci. U.S.A. 101, 16328-16332. doi: 10.1073/pnas.0407289101

Fox, J. P., Koprowski, H., Conwell, D. P., Black, J., and Gelfand, H. M. (1957). Study of antirabies immunization of man; observations with HEP Flury and

\section{AUTHOR CONTRIBUTIONS}

XG and JL conceived and designed the experiments. JL, BZ, and YW performed the experiments. JL and XG analyzed the data. JL and XG wrote the manuscript. All authors read and approved the final manuscript.

\section{FUNDING}

This study was partially supported by the National Nature Science Foundation of China (No. 31772742), the National Key Research and Development Program of China (No. 2016YFD0500400), and the Natural Science Foundation of Guangdong (No. 2015A03031103).

other vaccines, with and without hyperimmune serum, in primary and recall immunizations. Bull. World Health Organ. 17, 869-904.

Hellert, J., Buchrieser, J., Larrous, F., Minola, A., de Melo, G. D., Soriaga, L., et al. (2020). Structure of the prefusion-locking broadly neutralizing antibody RVC20 bound to the rabies virus glycoprotein. Nat. Commun. 11:596. doi: 10.1038/s41467-020-14398-7

Hooper, D. C., Morimoto, K., Bette, M., Weihe, E., Koprowski, H., Dietzschold, B., et al. (1998). Collaboration of antibody and inflammation in clearance of rabies virus from the central nervous system. J. Virol. 72, 3711-3719. doi: 10.1128/jvi.72.5.3711-3719.1998

Hooper, D. C., Phares, T. W., Fabis, M. J., and Roy, A. (2009). The production of antibody by invading B cells is required for the clearance of rabies virus from the central nervous system. PLoS Negl. Trop. Dis. 3:e535. doi: 10.1371/journal. pntd.0000535

Huang, C. T., Li, Z., Huang, Y., Zhang, G., Zhou, M., Chai, Q., et al. (2014). Enhancement of blood-brain barrier permeability is required for intravenously administered virus neutralizing antibodies to clear an established rabies virus infection from the brain and prevent the development of rabies in mice. Antiviral Res. 110, 132-141. doi: 10.1016/j.antiviral.2014. 07.013

Huang, J., Zhang, Y., Huang, Y., Gnanadurai, C. W., Zhou, M., Zhao, L., et al. (2017). The ectodomain of rabies virus glycoprotein determines dendritic cell activation. Antiviral Res. 141, 1-6. doi: 10.1016/j.antiviral.2017.01.022

Inoue, K., Shoji, Y., Kurane, I., Iijima, T., and Sakai, T. (2003). An improved method for recovering rabies virus from cloned cDNA. J. Virol. Methods 107, 229-236. doi: 10.1016/s0166-0934(02)00249-5

Ito, H., Minamoto, N., Watanabe, T., Goto, H., Rong, L. T., Sugiyama, M., et al. (1994). A unique mutation of glycoprotein gene of the attenuated RC-HL strain of rabies virus, a seed virus used for production of animal vaccine in Japan. Microbiol. Immunol. 38, 479-482. doi: 10.1111/j.1348-0421.1994.tb01 812.x

Ito, N., Takayama, M., Yamada, K., Sugiyama, M., and Minamoto, N. (2001). Rescue of rabies virus from cloned cDNA and identification of the pathogenicity-related gene: Glycoprotein gene is associated with virulence for adult mice. J. Virol. 75, 9121-9128. doi: 10.1128/JVI.75.19.9121-9128.2001

Ito, Y., Ito, N., Saito, S., Masatani, T., Nakagawa, K., Atoji, Y., et al. (2010). Amino acid substitutions at positions 242, 255 and 268 in rabies virus glycoprotein affect spread of viral infection. Microbiol. Immunol. 54, 89-97. doi: 10.1111/j. 1348-0421.2009.00192.x

Jackson, A. C. (2003). Rabies virus infection: an update. J. Neurovirol. 9, 253-258. doi: 10.1080/13550280390193975

Kaplan, M. M., Wiktor, T. J., and Koprowski, H. (1975). Pathogenesis of rabies in immunodeficient mice. J. Immunol. 114, 1761-1765.

Kuzmina, N. A., Kuzmin, I. V., Ellison, J. A., Taylor, S. T., Bergman, D. L., Dew, B., et al. (2013). A reassessment of the evolutionary timescale of bat rabies viruses based upon glycoprotein gene sequences. Virus Gen. 47, 305-310. doi: 10.1007/s11262-013-0952-9 
Lafon, M., Ideler, J., and Wunner, W. H. (1984). Investigation of the antigenic structure of rabies virus glycoprotein by monoclonal antibodies. Dev. Biol. Stand. 57, 219-225.

Lebrun, A., Portocarrero, C., Kean, R. B., Barkhouse, D. A., Faber, M., Hooper, D. C., et al. (2015). T-bet is required for the rapid clearance of attenuated rabies virus from central nervous system tissue. J. Immunol. 195, 4358-4368. doi: 10.4049/jimmunol.1501274

Luo, J., Shi, H., Tan, Y., Niu, X., Long, T., Zhao, J., et al. (2016). Two potential recombinant rabies vaccines expressing canine parvovirus virion protein 2 induce immunogenicity to canine parvovirus and rabies virus. Vaccine 34, 4392-4398. doi: 10.1016/j.vaccine.2016.07.020

Luo, J., Zhang, B., Wu, Y., Tian, Q., Mo, M., Long, T., et al. (2018). Recombinant rabies virus expressing interleukin- 6 enhances the immune response in mouse brain. Arch. Virol. 163, 1889-1895. doi: 10.1007/s00705-018-3808-8

Luo, J., Zhang, B., Wu, Y., Tian, Q., Zhao, J., Lyu, Z., et al. (2017). Expression of interleukin- 6 by a recombinant rabies virus enhances its immunogenicity as a potential vaccine. Vaccine 35, 938-944. doi: 10.1016/j.vaccine.2016. 12.069

Luo, Y., Zhang, Y., Liu, X., Yang, Y., and Yang, X. (2013). Characterization of a wild rabies virus isolate of porcine origin in China. Infect. Genet. Evol. 17, 147-152. doi: 10.1016/j.meegid.2013.03.046

Luo, Y., Zhang, Y., Liu, X., Yang, Y., Yang, X., Zhang, D., et al. (2012). Complete genome sequence of a highly virulent rabies virus isolated from a rabid pig in south China. J. Virol. 86, 12454-12455. doi: 10.1128/JVI.02234-12

Masatani, T., Ito, N., Shimizu, K., Ito, Y., Nakagawa, K., Abe, M., et al. (2011). Amino acids at positions 273 and 394 in rabies virus nucleoprotein are important for both evasion of host RIG-I-mediated antiviral response and pathogenicity. Virus Res. 155, 168-174. doi: 10.1016/j.virusres.2010.09.016

Mebatsion, T. (2001). Extensive attenuation of rabies virus by simultaneously modifying the dynein light chain binding site in the $\mathrm{P}$ protein and replacing Arg333 in the G protein. J. Virol. 75, 11496-11502. doi: 10.1128/JVI.75.23. 11496-11502.2001

Mei, M., Long, T., Zhang, Q., Zhao, J., Tian, Q., Peng, J., et al. (2019). Phenotypic consequence of rearranging the $\mathrm{n}$ gene of RABV HEP-Flury. Viruses 11:E402. doi: 10.3390/v11050402

Miao, F. M., Zhang, S. F., Wang, S. C., Liu, Y., Zhang, F., Hu, R. L., et al. (2017). Comparison of immune responses to attenuated rabies virus and street virus in mouse brain. Arch. Virol. 162, 247-257. doi: 10.1007/s00705-016-3081-7

Morimoto, K., Hooper, D. C., Carbaugh, H., Fu, Z. F., Koprowski, H., Dietzschold, B., et al. (1998). Rabies virus quasispecies: implications for pathogenesis. Proc. Natl. Acad. Sci. U.S.A. 95, 3152-3156. doi: 10.1073/pnas.95.6. 3152

Morimoto, K., Hooper, D. C., Spitsin, S., Koprowski, H., and Dietzschold, B. (1999). Pathogenicity of different rabies virus variants inversely correlates with apoptosis and rabies virus glycoprotein expression in infected primary neuron cultures. J. Virol. 73, 510-518. doi: 10.1128/jvi.73.1.510-518.1999

Morimoto, K., Kawai, A., Sato, Y., and Ohkubo, A. (2011). A unique transcription mode of rabies virus high egg passage-Flury strain detected in infected baby hamster kidney-21 cells. Microbiol. Immunol. 55, 558-564. doi: 10.1111/j.13480421.2011.00354.x

Nakagawa, K., Nakagawa, K., Omatsu, T., Katayama, Y., Oba, M., Mitake, H., et al. (2017). Generation of a novel live rabies vaccine strain with a high level of safety by introducing attenuating mutations in the nucleoprotein and glycoprotein. Vaccine 35, 5622-5628. doi: 10.1016/j.vaccine.2017.08.050

Phares, T. W., Kean, R. B., Mikheeva, T., and Hooper, D. C. (2006). Regional differences in blood-brain barrier permeability changes and inflammation in the apathogenic clearance of virus from the central nervous system. J. Immunol. 176, 7666-7675. doi: 10.4049/jimmunol.176.12.7666

Prehaud, C., Coulon, P., LaFay, F., Thiers, C., and Flamand, A. (1988). Antigenic site II of the rabies virus glycoprotein: structure and role in viral virulence. J. Virol. 62, 1-7. doi: 10.1128/jvi.62.1.1-7.1988

Prehaud, C., Wolff, N., Terrien, E., Lafage, M., Megret, F., Babault, N., et al. (2010). Attenuation of rabies virulence: takeover by the cytoplasmic domain of its envelope protein. Sci. Signal. 3:a5. doi: 10.1126/scisignal.2000510

Ramakrishnan, M. A. (2016). Determination of $50 \%$ endpoint titer using a simple formula. World J. Virol. 5, 85-86. doi: 10.5501/wjv.v5.i2.85

Roy, A., Phares, T. W., Koprowski, H., and Hooper, D. C. (2007). Failure to open the blood-brain barrier and deliver immune effectors to central nervous system tissues leads to the lethal outcome of silver-haired bat rabies virus infection. J. Virol. 81, 1110-1118. doi: 10.1128/JVI.01964-06

Schnell, M. J., McGettigan, J. P., Wirblich, C., and Papaneri, A. (2010). The cell biology of rabies virus: using stealth to reach the brain. Nat. Rev. Microbiol. 8, 51-61. doi: 10.1038/nrmicro2260

Schnell, M. J., Mebatsion, T., and Conzelmann, K. K. (1994). Infectious rabies viruses from cloned cDNA. EMBO J. 13, 4195-4203. doi: 10.1002/j.1460-2075. 1994.tb06739.x

Seif, I., Coulon, P., Rollin, P. E., and Flamand, A. (1985). Rabies virulence: effect on pathogenicity and sequence characterization of rabies virus mutations affecting antigenic site III of the glycoprotein. J. Virol. 53, 926-934. doi: 10.1128/jvi.53.3. 926-934.1985

Sharpless, G. R., Black, J., Cox, H. R., and Ruegsegger, J. M. (1957). Preliminary observations in primary antirabies immunization of man with different types of high-egg-passage Flury virus. Bull. World Health Organ. 17, 905-910.

Shimizu, K., Ito, N., Mita, T., Yamada, K., Hosokawa-Muto, J., Sugiyama, M., et al. (2007). Involvement of nucleoprotein, phosphoprotein, and matrix protein genes of rabies virus in virulence for adult mice. Virus Res. 123, 154-160. doi: 10.1016/j.virusres.2006.08.011

Takayama-Ito, M., Inoue, K., Shoji, Y., Inoue, S., Iijima, T., Sakai, T., et al. (2006a). A highly attenuated rabies virus HEP-Flury strain reverts to virulent by single amino acid substitution to arginine at position 333 in glycoprotein. Virus Res. 119, 208-215. doi: 10.1016/j.virusres.2006.01.014

Takayama-Ito, M., Ito, N., Yamada, K., Sugiyama, M., and Minamoto, N. (2006b). Multiple amino acids in the glycoprotein of rabies virus are responsible for pathogenicity in adult mice. Virus Res. 115, 169-175. doi: 10.1016/j.virusres. 2005.08.004

Takayama-Ito, M., Ito, N., Yamada, K., Minamoto, N., and Sugiyama, M. (2004). Region at amino acids 164 to 303 of the rabies virus glycoprotein plays an important role in pathogenicity for adult mice. J. Neurovirol. 10, 131-135. doi: 10.1080/13550280490279799

Tao, L., Ge, J., Wang, X., Zhai, H., Hua, T., Zhao, B., et al. (2010). Molecular basis of neurovirulence of flury rabies virus vaccine strains: importance of the polymerase and the glycoprotein R333Q mutation. J. Virol. 84, 8926-8936. doi: 10.1128/JVI.00787-10

Tian, D., Luo, Z., Zhou, M., Li, M., Yu, L., Wang, C., et al. (2016). Critical role of k1685 and k1829 in the large protein of rabies virus in viral pathogenicity and immune evasion. J. Virol. 90, 232-244. doi: 10.1128/JVI.020 50-15

Tian, Q., Wang, Y., Zhang, Q., Luo, J., Mei, M., Luo, Y., et al. (2017). Rescue of a wild-type rabies virus from cloned cDNA and assessment of the proliferative capacity of recombinant viruses. Virus Gen. 53, 573-583. doi: 10.1007/s11262017-1458-7

Tuffereau, C., Leblois, H., Benejean, J., Coulon, P., Lafay, F., Flamand, A., et al. (1989). Arginine or lysine in position 333 of ERA and CVS glycoprotein is necessary for rabies virulence in adult mice. Virology 172, 206-212. doi: 10. 1016/0042-6822(89)90122-0

Virojanapirom, P., Khawplod, P., Sawangvaree, A., Wacharapluesadee, S., Hemachudha, T., Yamada, K., et al. (2012). Molecular analysis of the mutational effects of Thai street rabies virus with increased virulence in mice after passages in the BHK cell line. Arch. Virol. 157, 2201-2205. doi: 10.1007/s00705-0121402-Z

Wang, Y., Tian, Q., Xu, X., Yang, X., Luo, J., Mo, W., et al. (2014). Recombinant rabies virus expressing IFNalphal enhanced immune responses resulting in its attenuation and stronger immunogenicity. Virology 46, 621-630. doi: 10.1016/ j.virol.2014.09.010

Wirblich, C., and Schnell, M. J. (2011). Rabies virus (RV) glycoprotein expression levels are not critical for pathogenicity of RV. J. Virol. 85, 697-704. doi: 10.1128/ JVI.01309-10

Wunner, W. H., Larson, J. K., Dietzschold, B., and Smith, C. L. (1988). The molecular biology of rabies viruses. Rev. Infect. Dis. 10(Suppl. 4), S771S784.

Yamada, K., Noguchi, K., and Nishizono, A. (2014a). Characterization of street rabies virus variants with an additional N-glycan at position 247 in the glycoprotein. Arch. Virol. 159, 207-216. doi: 10.1007/s00705-013-1805-5

Yamada, K., Noguchi, K., and Nishizono, A. (2014b). Efficient N-glycosylation at position 37 , but not at position 146 , in the street rabies virus glycoprotein 
reduces pathogenicity. Virus Res. 179, 169-176. doi: 10.1016/j.virusres.2013.10. 015

Yamada, K., Park, C. H., Noguchi, K., Kojima, D., Kubo, T., and Komiya, N. (2012). Serial passage of a street rabies virus in mouse neuroblastoma cells resulted in attenuation: potential role of the additional $\mathrm{N}$-glycosylation of a viral glycoprotein in the reduced pathogenicity of street rabies virus. Virus Res. 165, 34-45. doi: 10.1016/j.virusres.2012.01.002

Yang, F., Lin, S., Ye, F., Yang, J., Qi, J., Chen, Z., et al. (2020). Structural analysis of rabies virus glycoprotein reveals $\mathrm{pH}$-Dependent conformational changes and interactions with a neutralizing antibody. Cell Host Microb. 27, 441-453.e7. doi: 10.1016/j.chom.2019.12.012

Yang, Y., Huang, Y., Gnanadurai, C. W., Cao, S., Liu, X., Cui, M., et al. (2015). The inability of wild-type rabies virus to activate dendritic cells is dependent on the glycoprotein and correlates with its low level of the de novo-synthesized leader RNA. J. Virol. 89, 2157-2169. doi: 10.1128/JVI.02092-14
Zhang, D., He, F., Bi, S., Guo, H., Zhang, B., Wu, F., et al. (2016). GenomeWide transcriptional profiling reveals two distinct outcomes in central nervous system infections of rabies virus. Front. Microbiol. 7:751. doi: 10.3389/fmicb. 2016.00751

Conflict of Interest: The authors declare that the research was conducted in the absence of any commercial or financial relationships that could be construed as a potential conflict of interest.

Copyright $(2020$ Luo, Zhang, Wu and Guo. This is an open-access article distributed under the terms of the Creative Commons Attribution License (CC BY). The use, distribution or reproduction in other forums is permitted, provided the original author(s) and the copyright owner(s) are credited and that the original publication in this journal is cited, in accordance with accepted academic practice. No use, distribution or reproduction is permitted which does not comply with these terms. 